\title{
REFLEXÕES SOBRE A INTRODUÇÃO DA LÍNGUA INGLESA NO ENSINO FUNDAMENTAL I PÚBLICO Â LUZ DOS MULTILETRAMENTOS ${ }^{1}$
}

\author{
Christiane Batinga AGRA
}

Universidade Federal de Alagoas

RESUMO: Neste trabalho, apresento um recorte de minha pesquisa de mestrado que objetivou compreender uma experiência de introdução da Língua Inglesa no Ensino Fundamental I público, focando no desenvolvimento linguístico e na formação cidadã dos alunos envolvidos. A pesquisa foi realizada numa escola pública da cidade de Maceió / AL, com alunos do $5^{\circ}$ ano do Ensino Fundamental I. Apoio-me teoricamente na visão de língua de Bakhtin/Volochinov ([1929]/2010) que a considera um fenômeno social que só se materializa na presença do outro, na perspectiva sócio cultural de ensino-aprendizagem de Vygotsky (1978), na Linguística Aplicada Crítica (PENNYCOOK, 2006; RAJAGOPALAN, 2006), nos multiletramentos (ROJO, 2012), e nos estudiosos do ensino de inglês para crianças (CAMERON, 2001; BREWSTER, ELLIS \& GIRARD, 2002; ROCHA, 2006; TONELLI e RAMOS, 2007; entre outros). Adotei para esse estudo a abordagem qualitativa de pesquisa e os instrumentos de coleta de dados foram planos de aulas, relatos de aula, atividades produzidas pelos alunos, além de entrevistas e rodas de conversa. As aulas foram por mim ministradas durante o final do ano letivo de 2014 e o primeiro semestre de 2015. Os resultados apontam para o fato de que a partir do momento em que a Língua foi aproximada da realidade dos alunos, surgiram maiores oportunidades de uma aprendizagem significativa. Acredito que, a partir do momento em que a língua só se torna "viva" quando utilizada em relações dialógicas, o aprendizado dessa língua só será significativo se ela for, de fato, estudada dessa forma - com sentidos e objetivos reais de uso. Assim, o novo idioma foi utilizado não de forma mecânica e descontextualizada, mas sim como um instrumento para compreender melhor o mundo onde as crianças vivem, tornando-as capazes de transitar de uma maneira crítica e consciente pelos fenômenos globais e locais de nossa sociedade contemporânea.

PALAVRAS-CHAVE: ensino de inglês; ensino fundamental I; multiletramentos.

ABSTRACT: In this paper I present a clipping from my Masters research which aimed to understand an experience of introduction of English as a school subject in public Ensino Fundamental I. Its focus was the linguist development as well as citizen formation of the students involved. The research was developed in a public school of Maceió / AL, with students from $5^{\text {th }}$ grade from Ensino Fundamental I. The theoretical framework was based in the language vision of Bakhtin/Volochinov ([1929]/2010) who considers it a social phenomenon that is only materialized in the presence of another person, in the social-cultural perspective of teaching and learning from Vygotsky (1978), in Critical Applied Linguistics (PENNYCOOK, 2006; RAJAGOPALAN, 2006), in multiliteracies (ROJO, 2012) and theorists who study teaching English to children (CAMERON, 2001; BREWSTER, ELLIS \& GIRARD, 2002; ROCHA, 2006; TONELLI, RAMOS, 2007; among others). I have adopted

\footnotetext{
${ }^{1} \mathrm{O}$ presente artigo é uma releitura de recortes da dissertação de mestrado intitulada "Inglês se aprende na Escola Pública - reflexões sobre a introdução da língua inglesa no EFI à luz dos multiletramentos" defendida pela professora pesquisadora Christiane Batinga Agra em maio de 2016 no Programa de Pós-Graduação em Letras e Linguística da Universidade Federal de Alagoas (UFAL) e que teve como orientador o Prof. Dr. Sérgio Ifa.
} 
in this study the qualitative approach and data collection instruments were lesson plans, classroom stories, activities produced by the children and informal talks. I have taught the lessons through the end of 2014 and the first term of 2015. Results show that since the language was approximated of the students' reality, more opportunities of significant learning emerged. I believe that, once the language turns "alive" when it is used in dialogical relations, learn this language will only be significant if it is learned this way - with real meanings and real goals of use. This way, the new language was used not in a mechanical and decontextualized way, but as a tool to understand the world where the children live in a better way. This, can turn them able to transit in a critical and conscious form through global and local phenomena in our contemporary society.

KEYWORDS: English teaching; ensino fundamental I; multiliteracies

\section{Introdução}

É inegável a importância que a língua inglesa desempenha em nossas vidas atualmente. De ações cotidianas como ir ao shopping center e comer um hot dog, à divulgação de resultados de pesquisas científicas em congressos técnicos, a realidade é que o inglês vem desempenhando o papel de língua franca na comunicação internacional. Estima-se que, hoje em dia, o número de pessoas que falam inglês como língua adicional ultrapasse o número de falantes nativos do idioma. $\mathrm{O}$ inglês vem se incorporando às nossas vidas e às nossas culturas e possivelmente aquele que tem pelo menos um básico conhecimento dessa língua terá muito mais possibilidades de entender o mundo que o cerca, interagindo com esse mundo. Clara seria, então, a importância do seu aprendizado nas escolas.

Eu entendo, no entanto, que a importância desse aprendizado vai muito além da perspectiva meramente instrumental citada acima, que enxerga a língua como uma commodity (RAJAGOPALAN, 2005) nas relações entre as pessoas. Para mim, o ensino da língua inglesa deve ser encarado numa perspectiva formadora do sujeito e esse pensamento é ratificado pelos Parâmetros Curriculares Nacionais - Língua Estrangeira (PCN-LE) para o Ensino Fundamental II quando o documento atesta que

O distanciamento proporcionado pelo envolvimento do aluno no uso de uma língua diferente o ajuda a aumentar sua autopercepção como ser humano e cidadão. Ao entender o outro e sua alteridade, pela aprendizagem de uma língua estrangeira, ele aprende mais sobre si mesmo e sobre um mundo plural, marcado por valores culturais diferentes e maneiras diversas de organização política e social (BRASIL, 1998, p.19).

Já os Parâmetros Curriculares Nacionais $-1^{\mathrm{a}}$ a $4^{\mathrm{a}}$ séries (Ensino Fundamental I) - não tratam especificamente do ensino-aprendizagem de línguas adicionais, mas percebo um diálogo do documento com a citação feita anteriormente quando o seu texto atesta que "o exercício da cidadania exige o acesso de todos à totalidade dos recursos culturais relevantes para a intervenção e a participação responsável na vida social” (BRASIL, 1998a, v.1, p. 27). Acredito que, o conhecimento de uma língua adicional amplia sobremaneira as possibilidades de acesso aos recursos culturais da própria comunidade, assim como de outras. Assim, apesar dos documentos oficiais não preverem a introdução de línguas adicionais no Ensino Fundamental I de forma compulsória, entendo que, a sua inserção pode vir a contribuir para a formação cidadã das crianças estudantes da Escola Pública. Hoje, a introdução de uma língua adicional tem um caráter facultativo para a Educação Infantil e o Ensino Fundamental I ( $2^{\circ}$ ao $5^{\circ}$ ano). A grande maioria das escolas particulares brasileiras já o faz, mas o mesmo não ocorre na escola pública. Os alunos desta última passam a ter contato com outras línguas a partir do $6^{\circ}$ ano. Essa inserção tardia da língua adicional (se comparada às escolas privadas) se 
constitui, a meu ver, num fator de exclusão social, uma vez que não oportuniza aos alunos da escola pública as mesmas possiblidades de contato com outros discursos e consequentemente outras culturas que têm os estudantes de escolas privadas.

Assim, considero que o ensino de inglês para crianças na Escola Pública é plenamente justificável não apenas pelo caráter linguístico, mas também pelo caráter formador que ele pode exercer na vida dos alunos envolvidos. Reconheço ainda que vivemos hoje em uma sociedade que nos bombardeia todo o tempo com informações veiculadas por imagens, sons, gestos, cheiros e não apenas através da palavra falada ou escrita. Esta diversidade nos permite dizer que vivemos atualmente em uma sociedade que é multimodal. Para podermos atribuir sentido às mensagens e informações com que temos contato, acredito que o processo ensinoaprendizagem precisaria valorizar essas características multimodais nas escolas. Nesse sentido, considero que o componente curricular língua adicional poderia ampliar os horizontes discursivos das crianças facilitando o processo de construção de sentidos das informações e mensagens com que elas têm (ou possam vir a ter) contato em seus cotidianos, construindo multiletramentos que contribuem para sua formação cidadã. Assim, a pesquisa que aqui relato se propôs a compreender uma experiência de introdução da língua inglesa em uma turma do Ensino Fundamental I de uma escola pública, na periferia de Maceió/AL, através da perspectiva dos multiletramentos.

\section{Em quem me embaso teoricamente?}

Ao se tratar de língua inglesa, não podemos esquecer que nos referimos a uma língua utilizada atualmente por mais de um bilhão de pessoas. Kachru (1985) propõe uma categorização entre esses usuários. Ele os divide em três tipos: os que pertencem ao Círculo Interno, os que pertencem ao Círculo Externo e aqueles do chamado Círculo em Expansão². Os brasileiros falantes do inglês se situariam nesse terceiro círculo, ou seja, não o tem como primeira língua nem como língua oficial.

Discordo da visão colonizadora de Kachru pois, na minha concepção, todos os falantes, independente do círculo onde estejam situados, estão falando inglês. Como podemos pensar em uma cultura apenas, entre os falantes dessa língua, se ela já se encontra transculturalizada por natureza? Esse 'ideal' de monoculturalidade ('os ingleses falam assim', 'os americanos agem assim') ainda existe, infelizmente, em muitas de nossas aulas e nos discursos internalizados de senso comum.

Essa internalização ocorre porque a globalização e a ideia de homogeneização que muitas vezes ela perpassa acaba por nos fazer acreditar que todos os falantes de uma mesma língua possuem a mesma identidade linguística. Ora, não podemos esquecer que a nossa sociedade contemporânea que vive uma modernidade líquida, se caracteriza pela fluidez. Essa fluidez também se aplica as identidades. Rajagopalan (2003, p.59) já nos diz: "Volatilidade e instabilidade tornaram-se as marcas registradas das identidades". Se podemos dizer isso de grupos sociais que coabitam em uma mesma nação, o que dizer então de pessoas que vivem em lugares diferentes, mas compartilham a mesma língua?

Concordo com Ortiz (2006) ao afirmar ser o inglês hoje, uma língua mundial e não global. Para ele o termo global envolve uma unicidade, uma homogeneização, que de fato não ocorre em termos culturais. O mundial para ele, envolve uma miscigenação de culturas que incorporam a língua do outro, mas faz as adaptações adequadas aos contextos locais. Em suas palavras, "ao tornar-se mundial, ela (a língua inglesa), se liberta de seu enraizamento anterior

\footnotetext{
${ }^{2}$ Para Kachru (1985) o círculo interno é formado por países como Estados Unidos, Inglaterra e Austrália, onde a maioria dos habitantes fala o inglês como primeira língua. O círculo externo é formado pelas ex-colônias da Inglaterra, onde as pessoas continuam a usar o inglês como língua oficial. O círculo em expansão é aquele formado por países que tem o inglês como língua adicional.
} 
instituindo um artefato a ser legitimamente "deformado" pelos falantes de uma mesma galáxia" (ORTIZ, 2006, p. 27). Ou seja, para o autor é importante que a língua seja destituída de seu caráter de estrangeiridade, que a torna homogênea e, portanto, global. Caso contrário, o usuário jamais conseguirá deformá-la, visto que ele não considerará essa língua como parte de sua vida e cultura. É essa possibilidade de deformação, de manipulação, de efetivo uso, que tornaria a língua inglesa mundial.

Para aqueles que ainda enxergam o inglês como uma língua única, Moita Lopes (2003) adverte que:

O fato é que essa visão se baseia em um modo de ver o mundo construído em uma língua como monocultural, apagando o fato de que uma cultura é um construto social, e é, portanto, um produto daqueles que vivem as práticas discursivas em que essa LE é usada. E, ao contrário dessa visão de cultura como um pacote, os que vivem as práticas discursivas em uma língua são multiculturais (MOITA LOPES, 2003, p. 51).

É necessário que percebamos que não estamos aprendendo (ou ensinando) a língua e o seu único pacote cultural, principalmente ao lidar com pessoas que estão tendo um primeiro contato com ela. Assim, acho válido que elas aprendam a língua e conheçam outras culturas para ter finalmente a visão de que o mundo pode ser (e de fato o é), diferente de nós. É esse contato com o novo e com o diferente que pode nos fortalecer e nos empoderar, uma vez que nos permite refletir criticamente sobre nossa realidade local a partir do contato com o global. Moita Lopes utiliza o termo multiculturalidade. Acredito que na sociedade atual estamos além desse conceito. Na minha concepção, o multicultural indica que as diversas culturas coabitam num mesmo espaço, mas não se interpenetram. Numa visão de transculturalidade há uma permeabilidade entre culturas diversas, que interagem umas com outras num conceito análogo ao de fluidez. Concordo assim com Cox e Assis-Peterson (2007) quando elas afirmam que

conceitos como pluralismo cultural, diversidade cultural, multiculturalismo ou interculturalidade não nos parecem ser capazes de traduzir essas realidades. Eles nomeiam a existência de grupos culturais diversos, contudo silenciam acerca de suas contaminações e seu permanente estado de fluxo. Para traduzir ainda que aproximadamente tais realidades, optamos pelo termo transculturalidade (COX e ASSIS-PETERSON, 2007, p.35).

Ainda segundo as autoras esse conceito dialoga com o de transculturação defendido por Ortiz. Para o autor cubano, a transculturação envolve dois movimentos: o de desculturação (ou seja, o desenlace de uma cultura anterior) e outro de neo-culturação (o contato e a possível incorporação de novos fenômenos culturais). "O autor explica o enlace de culturas, fazendo uma analogia com a geração de um filho: a criança tem algo de seus pais, mas sempre algo de diferente de cada um dos dois" (COX e ASSIS-PETERSON, 2007, p.3536).

Diante do cenário exposto acima, acredito que o ensino da língua inglesa pode vir a ter um caráter transformador e formador dentro da sociedade contemporânea. Assim, o processo de ensino-aprendizagem do inglês, seguindo essas premissas, surge como um fator que pode fortalecer as crianças da escola pública, que passarão a ter contato com outros discursos e outras culturas através dessa língua e, graças a essas possiblidades de contato, poderão refletir sobre as suas experiências de mundo, ao confrontar culturas e discursos outros com os seus. Por isso sua inclusão é plenamente justificável nas séries iniciais do ensino fundamental.

Mas afinal, que língua é essa com que as crianças irão lidar? Assumo a concepção de língua de Bakhtin / Volochinov (2012), uma vez que eles defendem a ideia de língua como um fenômeno claramente social. Assim, para os autores, "a verdadeira substância da língua não é constituída por um sistema abstrato de formas linguísticas nem pela enunciação 
monológica isolada, nem pelo ato psico-fisiológico de sua produção, mas pelo fenômeno social da interação verbal" (BAKHTIN/VOLOCHINOV, 2012, p.127).

Ou seja, para eles, a língua só existe a partir da interação com o outro e sendo assim, jamais será estática: ela está em evolução ininterrupta. Por essa concepção perpassa a ideia de um sujeito que nunca está pronto, acabado. Se ele, o sujeito, não está permanentemente definido e estático, assim também não estará o seu discurso. Para Bakhtin, nós estamos em permanente processo de diálogo, uns com os outros ou com nós mesmos, visto que somos constituídos por um mosaico de outros discursos com que temos/tivemos contato em nosso convívio social.

Em relação a essa conexão que temos com o outro e que demonstramos em nossos enunciados, Bakhtin (2014) complementa

Em todos os domínios da vida e da criação ideológica, nossa fala contém em abundância palavras de outrem, transmitidas com todos os graus variáveis de precisão e imparcialidade. Quanto mais intensa, diferenciada e elevada for a vida social de uma coletividade falante, tanto mais a palavra do outro, o enunciado do outro, como objeto de uma comunicação interessada, de uma exegese, de uma discussão, de uma apreciação, de uma refutação, de um reforço, de um desenvolvimento posterior, etc., tem peso específico maior em todos os objetos do discurso (BAKHTIN, 2014, p. 139).

Em se tratando de processos de ensino-aprendizagem adoto nessa pesquisa o sociointeracionismo de Vygotsky pois acredito ser esta corrente a que melhor dialoga com a visão de língua como construto social. Segundo Tonelli (2007), Vygotsky

entende a linguagem como prática discursiva, ou seja, como produção simbólica que se constitui nas atividades sociais histórico-culturalmente situadas e que, por sua vez, também constituem essas práticas; portanto, considera a interação social e o instrumento linguístico decisivos para o desenvolvimento (TONELLI, 2007, p.112).

Fica clara então, a forte presença do componente social no pensamento do autor. Rego (2014, p.41) ratifica essa forma de pensar do psicólogo ao afirmar que para Vygotsky as funções psicológicas especificamente humanas se originam nas relações das pessoas em seus contextos culturais e sociais.

É importante frisar, aqui, a relação entre aprendizagem e desenvolvimento na visão vygotskyana. Para ele, o aprendizado é um aspecto fundamental para o processo de desenvolvimento. $\mathrm{O}$ autor russo assim complementa: "aprendizado não é desenvolvimento; entretanto, o aprendizado adequadamente organizado resulta em desenvolvimento mental e põe em movimento vários processos de desenvolvimento que, de outra forma, seriam impossíveis de acontecer" (VYGOTSKY, 2007, p. 103).

Entendo que aprendizagem para o psicólogo russo é um processo que envolve interação, a presença do outro. Assim, segundo Kohl (2010), em Vygotsky, justamente por sua ênfase nos processos sócio históricos, a ideia de aprendizagem inclui a participação das pessoas envolvidas no processo. "O termo que ele utiliza em russo (obuchenie) significa algo como "processo de ensino-aprendizagem", incluído sempre aquele que aprende, aquele que ensina e a relação entre essas pessoas" (KOHL, 2010, p.59).

Acredito que é a ampliação das possibilidades de contato com vários enunciados, oriundos dos mais diversos lugares e interlocutores, que o aprendizado da língua inglesa pode proporcionar aos nossos alunos. Também entendo que, na sociedade em que vivemos, temos contato com a nossa língua materna e com as línguas adicionais através de muitos outros meios além da palavra escrita (GEE, 2003). Somos bombardeados frequentemente com 
imagens, sons, vídeos, gestos, só para citar algumas formas. Sendo assim, não há como se pensar o processo ensino-aprendizagem baseado apenas em textos verbais. Concordo com Rocha (2007, p.17), quando ela diz que "torna-se imperativo pensar o processo de ensinoaprendizagem para além da letra, ou seja, abarcando a construção de sentidos por meio de outros signos que não somente as palavras". (2012),

Tudo que foi explicitado acima, leva ao conceito de multiletramentos. Segundo Rojo

Trabalhar com multiletramentos pode ou não envolver o uso de novas tecnologias de comunicação e de informação, mas caracteriza-se como um trabalho que parte das culturas de referência do alunado (popular, local, de massa) e de gêneros, mídias e linguagens por eles conhecidos, para buscar um enfoque crítico, pluralista, ético e democrático - que envolva agência de textos/discursos que ampliem o repertório cultural, na direção de outros letramentos (ROJO, 2012, p. 8).

Depreendo do pensamento da autora, que trabalhar na perspectiva dos multiletramentos envolve valorizar as diversas culturas que permeiam o universo dos participantes da pesquisa (local e regionalmente), mas também fazê-los ter contato com outras, para que eles consigam se posicionar criticamente diante das diferenças. Além disso, não podemos esquecer que esses contatos e reconhecimentos não se darão apenas na forma dos chamados letramentos formais, como já foi dito anteriormente. No mundo multissemiótico em que vivemos, há diversos outros tipos de letramento que devem ser valorizados nesse processo. Saber jogar um determinado jogo de videogame, conseguir operar um caixa eletrônico ou até mesmo conseguir baixar um aplicativo num celular, são exemplos de outros tipos de letramento além da escrita e da leitura formais.

Concordo com Rocha (2007, p. 22) quando ela diz que "a educação de línguas transformadora deve visar, portanto a construção de multiletramentos necessários na nova língua, para que o aluno seja capaz de engajar-se em práticas sociais mediadas pela linguagem". E essas práticas sociais obviamente valorizam conhecimentos produzidos dentro e fora dos muros da escola. $\mathrm{O}$ importante é permitir às crianças da escola pública acesso a discursos diversos para que ela consiga deles de apropriar (ou não) de forma consciente e crítica.

Dentre os multiletramentos ressalto o letramento crítico, fundamental para que consigamos refletir e nos posicionar diante do contexto já descrito de nossa sociedade contemporânea. Assim, segundo Tílio (2013)

Alguns pressupostos básicos de uma teoria de letramento crítico são a desnaturalização e não neutralidade do conhecimento; a instabilidade da realidade, constantemente (re) (co) construída; a multiplicidade do significado, historicamente e culturalmente (re) (co) construído, sempre múltiplo, negociável e contestável, considerando as relações de poder envolvidas nas práticas sociais (TÍLIO, 2013, p. 68).

O pensamento do autor corrobora a ideia de que na fluidez da sociedade contemporânea, a criticidade é crucial para que possamos refletir sobre as forças hegemônicas e discursos dominantes que a permeiam.

Assim, o letramento crítico está diretamente relacionado à capacidade do indivíduo de refletir sobre o seu universo, compará-lo com realidades diferentes da que vive e mais importante do que tudo, sabendo conviver com essas diferenças. A possibilidade de posicionamento e ação a que o letramento crítico pode levar é uma posição agentiva diante do contato com outros discursos. Assim, concordo com Duboc (2014), quando ela diz que atividades que promovem a agência, 
promovem a resposta do aluno ao seu entorno, ou seja, o seu posicionamento diante de uma determinada situação ou tema, a compreensão histórica desta sua posição e ainda o reconhecimento da existência de posicionamentos outros, além da possibilidade iminente de ver seu próprio julgamento transformar-se (DUBOC, 2014, p. 27).

Dessa forma, concluo dizendo que não há como pensar em ensino da língua inglesa para o público infantil sem considerar os multiletramentos que permitem as crianças compreender o seu universo. Sendo assim, acredito que o ensino baseado em temas (e apoiado nos multiletramentos) é uma forma de introduzir essa nova língua de uma maneira significativa para a criança. Assim, concordo com Brewster, Ellis e Girard (2002, p. 129) quando dizem que o uso de temas resgata a experiência de vida do aluno e viabiliza a possibilidade de criação de vínculos entre a escola e o seu mundo real. Tílio (2015) resume o exposto acima

Ao oferecer temas familiares, que 'digam algo' ao aluno, e relevantes aos seus contextos situacionais e culturais, cria-se uma oportunidade real para que ele se engaje sociodiscursivamente no processo de ensino e aprendizagem, o que propicia a construção de uma base de conhecimento sólida na Língua (TÍLIO, 2015, p.59).

Após um breve resumo de algumas correntes teóricas que nortearam a pesquisa, prossigo discorrendo sobre a metodologia adotada no estudo.

\section{Como foi realizada a pesquisa?}

A pesquisa qualitativa é associada ao interpretativismo e é com ela que o presente estudo se identifica dada a sua preocupação eminentemente social. Assim, apoio-me teoricamente em Ludke e André (1986, p.13), que afirmam que "a pesquisa qualitativa envolve a obtenção de dados descritivos, obtidos no contato direto do pesquisador com a situação estudada, enfatiza mais o processo do que o produto e se preocupa em retratar a perspectiva dos participantes". A partir do momento em que o pesquisador usa sua subjetividade e conhecimento de mundo na análise de seus dados, percebemos que se pode chegar a visões diferentes sobre um mesmo fenômeno. Para quem faz pesquisa qualitativa, o processo e os participantes da pesquisa são a razão de ser do estudo e não a exclusiva busca por resultados.

No paradigma qualitativo de pesquisa, defino a minha como um estudo de caso. Apoiome em algumas das características elencadas por Ludke e André (1986), para assim classificar a investigação. O que caracteriza o meu estudo como único é o fato de que na escola onde ele se realizou, nunca havia ocorrido uma experiência de introdução da língua inglesa nas séries iniciais. Assim, a pesquisa iniciou de fato, a partir do momento em que escolhi a escola onde seria desenvolvido o projeto - a Escola Municipal Dra. Elisabeth Anne Lyra Lopes de Farias. A escola fica localizada na periferia da cidade de Maceió. Hoje, ela funciona nos três turnos com turmas do $1^{\circ}$ ao $9^{\circ}$ ano do Ensino Fundamental pela manhã e a tarde e turmas de Educação de Jovens e Adultos no período da noite. Ao todo estudam ali 1066 alunos. Escolhi trabalhar com uma turma de $4^{\circ}$ ano do período da manhã. A escolha do turno foi aleatória, mas a escolha da série não. Sabia que o estudo começaria em 2014 e se estenderia até 2015, ou seja, a pesquisa continuaria com essa turma quando eles já estivessem no $5^{\circ}$ ano. Minha intenção era que as crianças tivessem o menor espaço de tempo possível entre o final das aulas da pesquisa e a efetiva introdução da língua inglesa como disciplina na sua grade curricular. 
Ao todo, foram por mim ministradas 20 aulas, perfazendo um total de aproximadamente $40 \mathrm{~h}$ de contato direto com os alunos. As aulas iniciaram em novembro de 2014 e terminaram em outubro de 2015. Em cada momento-aula procurei coletar e posteriormente interpretar: os planos de aula (20 ao todo), as gravações em áudio das aulas (20 transcrições), as produções realizadas pelos alunos nas aulas (textos, desenhos e vídeos) e os meus diários de observação (que eram redigidos após cada momento com as crianças. Foram 20 ao todo). Eventualmente, pude recolher também o diário de observação da professora titular da turma (02 diários).

Desde o início da pesquisa minha intenção era tornar as aulas e o aprendizado da nova língua significativos para as crianças. Não havia a pretensão de elaborar um plano de curso e simplesmente executá-lo durante as aulas previstas. Também não queria seguir nenhuma sugestão proposta por livros didáticos. Eu gostaria que os temas surgissem a partir das necessidades e interesses das crianças, uma vez que, se eles fossem escolhidos previamente correria o risco de, como nos diz Rocha e Tílio (2009, p.307), abordar conteúdos não situados no mundo dos alunos. Segundo os autores, dessa forma os conteúdos são como "abstrações em um vácuo social". Assim, elegemos (eu e as crianças) três temas para trabalhar: escola, atividades de lazer e comida.

Essas decisões metodológicas se coadunam assim, com meus referenciais teóricos (Bakhtin e Vygotsky) que enxergam língua e aprendizado como frutos de interações e construções sociais e com a visão de pesquisa qualitativa que prima pela valorização do processo.

A proposta aqui é fazer um breve recorte da interpretação dos dados coletados, me atendo às questões relacionadas ao trabalho com letramento crítico.

\section{É possível o trabalho com letramento crítico no Ensino Fundamental I?}

Para iniciar a reflexão acerca da formação cidadã, é necessário que pensemos acerca do conceito de agência. Segundo Rocha (2012), a ideia de agência está relacionada à nossa capacidade de refletir sobre outros discursos além daqueles que já internalizamos como se fossem nossos e a partir dessa reflexão modificar ou adequar (ou até mesmo negar) esses outros discursos às nossas realidades de vida.

Assim, segundo a autora

A ideia de agência (...), geralmente apresenta-se ligada ao conceito de apropriação de discursos alheios e de sua ressignificação, na medida em que estes, ao encontrarem-se imersos no inacabamento da comunicação verbal/multissemiótica ideológica e dialógica, impregnarem-se por entonações expressivas e valorações únicas, tornam-se internamente persuasivos (ROCHA, 2012, p. 70).

Enquanto refletimos, podemos agir sobre a realidade vigente. Ao promover o letramento crítico, podemos nos tornar capazes de ultrapassar as visões massificadoras dos nossos discursos autoritários internalizados e contribuir para uma participação mais democrática e ética no mundo em que vivemos. Essa contribuição pode levar a formação de cidadãos mais conscientes de seu papel no contexto de mundo em que habitam.

Um aspecto importante do trabalho com letramento crítico é que a participação é protagonista, visto que cada indivíduo tem condições para considerar várias posições para refletir e chegar as suas próprias decisões e ações. Cidadania ativa é como Rocha (2012) chama essa capacidade de ação.

Durante a pesquisa identifiquei alguns momentos em que as crianças refletiram e agiram sobre as suas realidades. No primeiro, os alunos foram convidados a criar livretos, em que 
teriam de representar suas atividades preferidas de lazer e ao mostrar suas produções aos colegas teriam de falar sobre essas atividades favoritas. A seguinte discussão surgiu a partir do livreto de João (fig. 1 e 2).
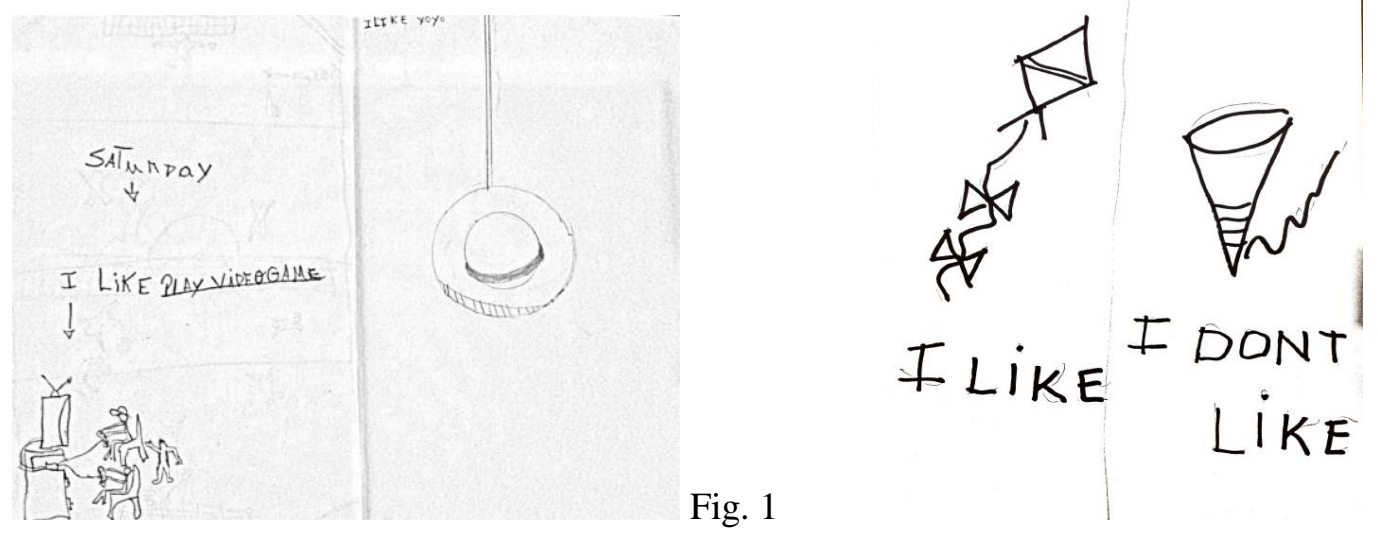

Fig. 2

João: I like video games. I like muito. I like kite. I like yoyo. I don't like spinning top.

Vários alunos: Oxe! Se não gosta por que comprou?

João: Porque é época de pião né? Se a gente não comprar fica sem brinquedo!

Professora pesquisadora: Como assim ‘época de pião'? Alguém me explica?

Eliel: Tia, é assim... Aqui no conjunto tem época. Época de pipa, época de pião, época de chimbra, época de cards...

Professora pesquisadora: Não entendi... Quem diz qual é a época? São vocês?

Eliel: Não! São os donos das banquinha tia! Eles escolhem o que comprar e só vende aquilo entendeu?

(Balanço a cabeça negativamente)

José: É assim, eu vou dizer... Minha vó tem mercadinho. Eles se reúnem e decidem o que vai vender mais pras criança. Agora é pião. Todo canto tem pião pra vender. Não tem chimbra, nem cards...

Ana: Tem sim!! Eu achei na banquinha!!

José: Mas é mais caro né?

Professora pesquisadora: E vocês gostam disso? Por exemplo, agora é época de pião, quem não gosta faz o que?

José: Brinca com os velho, mas nem dá... Já tem tudo se acabado... Ou perdido

Professora pesquisadora: E vocês acham isso legal? Já pensaram sobre isso?

Vários alunos: Oxe, muda não tia!

Luísa: Oxe, pode mudar sim! É só a gente querer! Quem compra as coisa? A gente... Se a gente não comprar eles vão ter de parar de vender só uma coisa ué! Fala ai com a sua vó Zezinho!!! Ela pode ajudar a gente!!

Vários alunos: Isso, fala....

José: Tá, vou ver...

(Excerto de aula

01) 
Interessante é perceber pela fala das crianças o sentimento de acomodação que a maioria possui (“'Oxe, muda não tia!"). Claro que, essa simples conversa em sala de aula, não será provavelmente a responsável pela mudança de hábitos dos comerciantes do Conjunto, até porque aquelas não são as únicas crianças envolvidas. No entanto, acredito que a conversa instigou a inquietação, a reflexão sobre o porquê de uma determinada situação não poder ser diferente. Quando Luisa diz "Pode mudar sim" ela está reconfigurando um dos discursos de senso comum autoritários, vinculados naquela comunidade, e ao refletir sobre ele, tentando mudar os seus próprios discursos e a comunidade que a circunda. Isso é um indício de cidadania ativa.

Também tentei promover o exercício da cidadania com o tema COMIDA. Percebi que as crianças tinham interesse em discutir questões relacionadas a alimentos saudáveis e não saudáveis e em uma das aulas surgiu um debate acerca do lanche que era servido na escola. As crianças achavam o lanche saudável, mas repetitivo (eles comiam sopa quase todos os dias) e então pensei na criação de um novo cardápio para o refeitório. Esses cardápios foram elaborados em Inglês (fig. 3) e a coordenação da escola concordou em participar do processo, discutindo a viabilidade de sua implantação. Fiz uma votação para selecionar o melhor cardápio e a coordenadora Fábia foi até a sala de aula nesse dia para discutir com os alunos a proposta vencedora. A seguinte discussão surge:

Fabia: " Olha só. Deixa eu explicar como é escolhido o cardápio pela SEMED.... (ela faz toda a explicação sobre a forma como os cardápios devem ser iguais em todas as escolas, para proporcionar uma "melhor qualidade" do lanche)

Leo: "Oxe!! É tudo igual em Maceió todo é? Tá errado isso!!! E se numa escola os meninos gostarem mais de uma coisa do que de outra?"

Fábia: "A SEMED não tem como dar conta disso. São muitas escolas. Tem de haver um padrão de qualidade. Olha só, desse cardápio que ganhou aqui, eu já digo, a salada de frutas tá fora! Eles não permitem porque é muito perecível."

Emily: "Mas é só fazer na hora que a gente for comer... Que frescura tia!!! Estraga não..."

Fábia: "O chocolate também tá fora. Tem muita criança que é alérgica e não pode..."

Vários alunos: "Ah tia!!! Então não adiantou nada o nosso cardápio... “"

Professora pesquisadora: "Não tem como negociar Fábia? O que vocês acham da proibição do chocolate?"

Edu: "Chocolate a gente já sabia né tia? Mas fruta é saudável..."

Fábia: "Bom, o que a gente pode fazer, é deixar um dia com

frutas, mas sem salada..."

Edu: "A gente pode escolher as frutas?"

Fábia: "Tenho de falar com o diretor, vamos ver..."

(Excerto de aula 02)

Mais uma vez percebo a intenção dos alunos em negociar, tentar modificar a realidade existente. O discurso representativo de poder da Coordenadora ("eu já digo, a salada de frutas tá fora"), não intimida as crianças que tentam e de fato conseguem, uma negociação. $\mathrm{O}$ desenvolvimento dessa capacidade de negociação para mim representa uma prática de Letramento Crítico uma vez que, novamente, há uma tentativa de adaptar o discurso do outro às realidades e necessidades locais. 


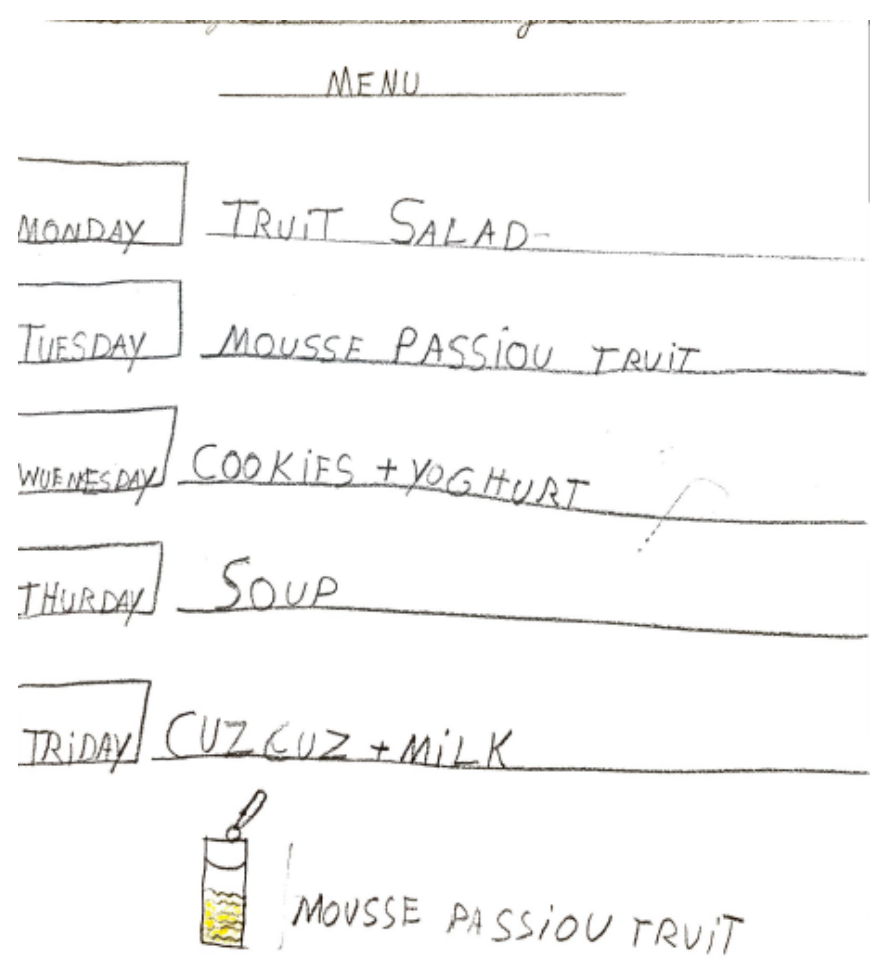

Fig. 3

\section{Algumas considerações}

Acredito que as crianças participantes do estudo foram empoderadas. Esse empoderamento ocorreu pela possibilidade de acesso a outras culturas e outros discursos que a aprendizagem e o contato com a língua adicional lhes proporcionam. Infelizmente esse acesso (e consequentemente essa possibilidade de empoderamento) ainda vem sendo negada às crianças das séries iniciais do EFI público, pelo apagamento da língua adicional de seus currículos.

Ao tratar sobre reflexão e conscientização em relação aos discursos que nos circundam e principalmente sobre a língua inglesa, é inevitável se pensar em contribuições para formação das crianças como cidadãs dessa sociedade contemporânea, fluida e transcultural. Acredito, por tudo que foi descrito e interpretado, que a língua inglesa foi vista nessa pesquisa além de uma perspectiva estrutural; a língua foi vista aqui exatamente da forma como acredito que ela seja: viva, como nos diz Bakhtin. Entendo e trabalho com a língua viva porque ela possibilita diálogos que podem levar a reflexão e agência se atrelados aos multiletramentos.

As crianças participantes tiveram a oportunidade de refletir, a partir do uso da língua, sobre as diferenças entre o seu mundo e o mundo do outro. A partir dessa reflexão, nos propusemos a fazê-las perceber que as diferenças não nos fazem melhores ou piores do que o outro. Tentamos assim, fugir dos eixos binários que circundam os discursos ainda carregados de modernidade do mundo de hoje - certo/errado, melhor/pior. Quando os alunos tiveram a oportunidade de propor e de discutir a implantação de um novo cardápio para o refeitório da escola, por exemplo, eles estavam de fato, refletindo e tentando modificar os discursos hegemônicos centralizadores e homogeneizantes que os circundam. Isso é para mim, um indício claro de cidadania ativa. Por isso defendo que a inclusão do componente curricular língua inglesa no EFI tem muito a colaborar na construção de cidadãos críticos e éticos, que possam efetivamente refletir sobre seus contextos de mundo e eventualmente modificá-los a partir de sua agência. 
Acredito ainda, que os participantes da pesquisa saíram de alguma forma transformados porque abri espaços para que os significados apresentados inicialmente por eles fossem questionados. Eles foram provocados a enxergar, quando possível, por um outro prisma. Entendo também que todas as ações praticadas pelos alunos revelam as suas formas de entender e de agir no contexto onde vivem, contexto esse que é cada dia mais multimodal. Por isso defendo que as crianças precisam ser ensinadas pela perspectiva dos multiletramentos que as possibilitam circular livremente por esse mundo de textos diversos e em diferentes línguas, muito mais amplos que simplesmente textos escritos e que possam produzir outros significados quando em contato com eles.

\section{Referências}

ASSIS - PETERSON, A.A.; COX, M.I.P. Transculturalidade e transglossia: para compreender o fenômeno das fricções linguístico-culturais em sociedades contemporâneas sem nostalgia. In: CAVALCANTI, M.C.; BORTONI-RICARDI, S.M. (orgs.) Transculturalidade, Linguagem e Educação. São Paulo: Mercado de Letras, 2007. p. 2343.

BAKHTIN, M. Questões de Literatura e de Estética - A Teoria do Romance. São Paulo: Editora Hucitec, $7^{\mathrm{a}}$ edição, 2014.

BAKHTIN, M./ VOLOCHINOV, V.N. Marxismo e filosofia da linguagem. São Paulo: Hucitec, 13a edição, 2012.

BRASIL. Secretaria de Educação Fundamental. Parâmetros Curriculares Nacionais: pluralidade cultural, orientação sexual. Brasília: MEC/SEF, 1998.

BRASIL. Secretaria de Educação Fundamental. Parâmetros Curriculares Nacionais $-\mathbf{1}^{\mathbf{a}}$ a $4^{a}$ série. v. 1. Introdução aos parâmetros curriculares nacionais. Brasília: MEC/SEF, 1998.

BREWTER, J.; ELLIS, G.; GIRARD, D. The Primary English Teacher's Guide. New Edition. London: Penguin, 2002.

DUBOC, A. P. M. Ensino e avaliação de línguas estrangeiras: tendências em curso. In: MULIK, K. B.; RETORTA, M. S. (orgs.) Avaliação no ensino-aprendizagem de línguas estrangeiras: diálogos, pesquisas e reflexões. São Paulo: Pontes Editores, 2014. p. 21-47.

GEE, J.P. What videogames have to teach us about learning and literacy. New York: MacMillan, 2003.

GRADDOL, D. English Next. Plymouth: British Council, 2006.

KOHL, M.O. Vygotsky - aprendizagem e desenvolvimento: um processo sócio histórico. São Paulo: Scipione, 2010.

KUMARAVADIVELU, B. A Linguística Aplicada na Era da Globalização. In: MOITA LOPES, L.P. (org.) Por uma Linguística Aplicada Indisciplinar. São Paulo: Parábola Editorial, 2006. p. 129-148.

LUDKE, M.; ANDRE, M.E.D.A. Pesquisa em Educação: abordagens qualitativas. São Paulo: EPU, 1986.

MENEZES DE SOUZA, L.M.T. Para uma redefinição de Letramento Crítico: conflito e produção de Significação. In: MACIEL, R.F.; ARAÚJO, V.A. (orgs.) Formação de 
Professores de Línguas - ampliando perspectivas. Jundiaí: Paco Editorial, 2011. p. 128140.

MOITA LOPES, L.P. A Nova Ordem Mundial, os Parâmetros Curriculares Nacionais e o Ensino de Inglês no Brasil: a Base Intelectual para uma Ação Política. In: BARBÁRA L.; RAMOS, R.C.G. (Orgs.) Reflexão e Ações no Ensino-aprendizagem de Línguas. Campinas: Mercado de Letras, 2003. p. 25-46.

ORTIZ, R. Mundialização: saberes e crenças. São Paulo: Brasiliense, 2006.

RAJAGOPAlAN, K. Por uma Linguística Crítica. São Paulo: Parábola Editorial, 2003.

A Geopolítica da Língua Inglesa e seus reflexos no Brasil. In: LACOSTE, Y.; RAJAGOPALAN, K. (orgs.) A Geopolítica do Inglês. São Paulo: Parábola Editorial, 2005. p. 135-159.

A Língua Estrangeira para Crianças: um tema no mínimo ambíguo. In: ROCHA, C.H.; TONELLI, J.R.A.; SILVA, K.A. (orgs.) Língua Estrangeira para Crianças: Ensinoaprendizagem e Formação Docente. São Paulo: Pontes Editores, 2010. p. 9-12.

REGO, T.C. Vygotsky: uma perspectiva histórico-cultural da educação. Rio de Janeiro: Vozes, 2014.

ROCHA, C.H. O ensino de LE (inglês) para crianças do ensino fundamental público na transdisciplinaridade da linguística aplicada. In: TONELLI, J.R.A; RAMOS, S.G.M. (orgs.) O Ensino de LE para Crianças: Reflexões e Contribuições. Londrina: Moriá, 2007. p. 134.

Reflexões e Propostas sobre Língua Estrangeira no Ensino Fundamental I: Plurilinguismo, Multiletramentos e Transculturalidade. São Paulo: Pontes Editora, 2012.

ROCHA, C.H.; TÍLIO, R.C. As dimensões da linguagem em livros didáticos de inglês para o Ensino Fundamental I. Trabalhos em Linguística Aplicada (UNICAMP), v. 48, p. 295-316, 2009.

ROJO, R.H.R Fazer Linguística Aplicada em perspectiva sócio histórica: privação sofrida e leveza de pensamento. In: MOITA LOPES, L.P. (org.) Por uma Linguística Aplicada Indisciplinar. São Paulo: Parábola Editorial, 2006. p. 253-276.

Protótipos didáticos para os Multiletramentos. In: ROJO, R; MOURA, E. (orgs.) Multiletramentos na Escola. São Paulo: Parábola Editorial, 2012. p. 7-9.

Pedagogia dos Multiletramentos: diversidade cultural e de linguagens na escola. In: ROJO, R; MOURA, E. (orgs.) Multiletramentos na Escola. São Paulo: Parábola Editorial, 2012a. p. 11- 31.

TEIXEIRA E SILVA, R. Representações de Países e Regiões de Língua Portuguesa em Materiais Didáticos usados em Macau para o Ensino de Português como Língua não Materna. In: ROCHA, C. H.; BRAGA, D. B.; CALDAS, R. R. (Orgs.) Políticas Linguísticas, Ensino de Línguas e Formação Docente: desafios em tempos de Globalização e Internacionalização. São Paulo: Pontes Editores, 2015. p. 105-128.

TÍLIO, R. Linguística (aplicada), contemporaneidade e materiais didáticos: diálogos. In: SANTOS, L.I.S; SILVA, K.A. (orgs.) Linguagem, Ciência e Ensino: desafios regionais e globais. Campinas: Pontes Editores, 2013. p. 57-76.

Repensando a abordagem comunicativa: multiletramentos em uma abordagem consciente e conscientizadora. In: ROCHA, C.H.; MACIEL, R.F. (Orgs.) Língua 
Estrangeira e Formação Cidadã: Por entre Discursos e Práticas. $2^{\mathrm{a}}$ ed. Campinas: Pontes Editores, 2015. p. 51-67.

TONELLI, J.R.A. Histórias infantis e o ensino da língua inglesa para crianças. In: TONELLI, J.R.A; RAMOS, S.G.M. (orgs.) O Ensino de LE para Crianças: Reflexões e Contribuições. Londrina: Moriá, 2007. p. 107- 136.

VYGOTSKY, L. A Formação Social da Mente. São Paulo: Editora Martins Fontes, $7^{\text {a }}$ edição, 2007.

WELSCH, W. Transculturality the puzzling form of Cultures today. In: Spaces of Culture: City, Nation, World. Ed. by Mike Featherstone and Scott Lash, London: Sage 1999, p. $194-213$. 